inconscientemente se nos viene a la memoria la tabla central del tríptico del Jardín de las Delicias «el que verdaderamente ama es necesario que se turbe con la dulzura del soberano deleite... Y no sólo en la humana especie, mas en los peces, en las bestias, en las aves, en los reptiles y en lo vegetativo de algunas plantas han a este respecto ser machos y hembras»; Calixto, en el Acto IV, después de haber conseguido a Melibea, alude a la caducidad del placer: « OOh breve deleite mundano ¡ ¡Como duran poco y cuestan mucho tus dulzores!» ${ }^{15}$. Todavía, al final de la obra, cuando Pleberio llora el final de su hija Melibea, encontramos en sus palabras relaciones con el Jardín del Bosco «agora, visto el pro y la contra de tus bien andanças, me pareces un laberinto de errores ... juego de hombres que andan en corro, laguna llena de cieno, región llena de espinas, monte alto ... huerto florido y sin fruto, fuente de cuydados, no de lágrimas, mas de miseria ... dulce ponçoña, vana esperança, falsa alegría ... Cévasnos, mundo falso, con el manjar de tus deleytes; al mejor sabor nos descubres el anzuelo; no lo podemos huyr, que nos tiene ya caçadas las voluntades... Corremos por los prados de tus viciosos vicios (deleitosos vicios), muy descuydados, a rienda suelta,; descúbresnos la celada quando ya no hay lugar de volver» ${ }^{16}$.

ISABEL MATEO GómeZ Departamento de Arte C.S.I.C.

\title{
OBRAS PARA DEFINIR LA PERSONALIDAD ARTÍSTICA DEL PINTOR DANIEL MARTÍNEZ, PADRE DE JUSEPE MARTÍNEZ
}

La Biblioteca Nacional de Madrid conserva un dibujo de la Sagrada Familia (fig. 6), boceto preparatorio para una pintura del mismo tema que se encuentra en el Museo de Tapices de la Seo de Zaragoza (fig. 7) y ésta, a su vez, la debió mandar copiar el canónigo Mandura en 1602 en otra tabla, donde incluye su propio retrato, cuadro que donó a la iglesia de San Salvador de Ejea de los Caballeros (fig. 8).

El dibujo, realizado a lápiz y tinta marrón sobre papel beige $(200 \times 158 \mathrm{~mm}$.), está cuadriculado para su posterior ampliación, procede de la colección de Valentín Carderera

15 Los estudios de La Celestina han constatado la presencia del texto entre los clérigos y la extracción moral que hacían de él. Respecto al párrafo de los «deleites» en plantas, animales, etc., Russell (loc. cit. nota 8) dice que pudo ser inspirado por los textos del Tostado, quien a su vez los tomó de libros clásicos y bíblicos, que eran lugares comunes en la literatura europea de la época.

16 Russell considera que este párrafo está inspirado en Petrarca, De rebus familiar, publicada en 1496. En este texto existen muchas metáforas por las cuales se denuncia la vida en general, es ejemplo de lo que los retóricos llamaban «conglobatio» o aglomeración (loc. cit. nota 8, pp. 599-600, notas 31 a 33). Este presupuesto retórico nos trae a la memoria la denominación que, en fecha temprana, tuvo el tríptico: De la Variedad del Mundo, y en su forma de expresarlo. Yarza (loc. cit. nota 3, p. 66) cita un texto del siglo XVI de H. Mande muy similar al de La Celestina, pero el de Rojas es anterior. No cabe duda de que tanto Mande como Rojas, y el comitente del Bosco, utilizaron el texto de Petrarca. Todo ello habla en favor de que los textos literarios y las ideas circulaban y eran comunes a toda Europa en ciertos ambientes cultos y humanistas, tanto laicos como religiosos. El texto del Crisólogo y el contexto de la Crónica General de Schedel, están siendo revisados por mi para la próxima publicación, en este año 1999, de un libro sobre El Jardín de las Delicias. 
y está atribuido a Diego Martínez de Arcos. Escrito a tinta en el ángulo inferior izquierdo, bien en la época del dibujo o cuando se cuadriculó, aparece: «D (letra hoy muy borrosa) Martinez Daros?» ". Barcia lo incluía entre los dibujos del siglo XVII, indicando que era obra de un artista desconocido, en cambio, Angulo y Pérez Sánchez lo reproducen y adjudican a un pintor de probable escuela castellana y del último cuarto del siglo XVI ${ }^{2}$. El encontrarse̊ en Aragón lás dos pinturas antes citadas y la relación tipológica de las figuras del dibujo con modelos de los artistas flamencos Pablo Schepers (ca.+1577) y Rolam Mois (+1592), que llegaron aquí para ser pintores de la casa del duque de Villahermosa, Martín de Gurrea y Aragón, además de otras coincidencias sugieren la posibilidad de ser obra aragonesa.

Las similitudes entre el dibujo y la producción artística de los dos pintores citados, se pueden observar entre el Niño Jesús y San Juanito, con dos ángeles desnudos junto a la Virgen en el gran cuadro de la Asunción del antiguo retablo mayor del monasterio de La Oliva y hoy en el convento de Agustinas Recoletas de Tafalla (Navarra). Lo mismo se puede decir respecto de San José con el apóstol situado en primer término a la derecha en la pintura navarra, cuyo boceto previo (510 x 350) de toda la composición se conserva en el Museo de Bellas Artes de Valencia ${ }^{3}$. Se recuerda que el retablo fue contratado en 1571 por Schepers y Mois, quedó interrumpido al fallecer el primero y lo terminó el segundo después de 1584, con ayuda del taller. Las concordancias con la obra navarra también existen en el modo de diseñar las manos. Referencias de las figuras infantiles y de manera particular de la cabeza de San José, se localizan además en una pintura de la Virgen del Pilar con Santiago y el retrato de un clérigo jesuita, firmada por Schepers y fechada en 1575, cuyo dibujo parcial preparatorio se subastó en la Galería Christie (Londres, 1993). El modelo lo copiaba en 1579 su cuñado Silvestre Estanmolín en un tríptico dedicado a la misma advocación mariana ${ }^{4}$.

El autor del dibujo de la Biblioteca Nacional demuestra habilidad en el manejo de la pluma hasta conseguir una composición bien resuelta, donde no sólo se diseñan los perfiles de las formas sino que también están marcadas las zonas de sombra, aspectos que lo convierten en verdadero modellino para su utilización en obras de pintura. Es posible que el nombre anotado se refiera a Daniel Martínez (1555-1636), cuya personalidad artística está todavía por definir. Era padre del afamado artista y teórico zaragozano Jusepe Martínez y según el testimonio de su hijo, Daniel era «de nación flamenco» ${ }^{5}$, sin embargo la primera noticia conocida es de junio de 1581 cuando se casa con Isabel Lurbez, nacida en Ejea de los Caballe-

1 Carderera pudo escribir con pluma (fuera de la cuadrícula del dibujo) el siguiente texto, «Martinez de Arcos ó Aros (Diego)», mientras que el texto a lápiz «Diego Martinez de Arcos o de Aros», se pudo añadir en 1887 cuando el Gobierno español compró el dibujo.

2 A. Barcia, Catálogo de la colección de dibujos originales de la Biblioteca Nacional, Madrid, 1906, n.․ 429. D. Angulo Iñíguez y A. E. Pérez Sánchez, A Corpus of Spanish Drawings, vol. I: 1400 to 1600, London, 1975, n.. 397, p. 77; estos autores dicen que el texto con el nombre del pintor corresponde al siglo XVII.

A. Espinós, «Un dibujo de Roland de Mois en el Museo de Bellas Artes de San Carlos de Valencia», Archivo Español de Arte, 1975, p. 411.

4 La pintura de Schepers, en colección particular de Valencia, fue dada a conocer por F. Benito, «Anotaciones al pintor flamenco Pablo Schepers», Academia n. ${ }^{\circ}$ 73, 1991, pp. 461-476; no compartimos plenamente las atribuciones del autor respecto al retablo de Tafalla. Para el tríptico de Estanmolín véase C. Morte «Una obra firmada y fechada del pintor Silvestre Estanmolín, 1579», Artigrama, n.ํ 4, 1987, pp. 83-90.

Jusepe hizo esta declaración en un interrogatorio, que tuvo lugar en Zaragoza el día 23 de noviembre de 1648, para declarar la identidad de tres retratos del Beato Pedro de Arbués; lo publica el Conde de la Viñaza, Adiciones al Diccionario de Ceán Bermúdez, tomo III, Madrid, 1894, pp. 22-23. J. Gallego en la Edición de los Discursos practicables del nobilísimo arte de la pintura, de Jusepe Martínez, Madrid, Akal, 1988, pp. 14-15, pone en duda el origen flamenco de Daniel. 
ros, lugar donde se celebró la ceremonia y en cuya localidad vivió el matrimonio hasta su traslado definitivo a Zaragoza entre finales de 1595 y principios de $1600{ }^{6}$. Ejea se convirtió durante la segunda mitad del siglo XVI en el centro de actividad artística más destacado de la comarca de las Cinco Villas, como respuesta a la renovación del arte mueble de la zona, la prosperidad económica de la misma y su vecindad con Navarra, un mercado que ofrecía posibilidades de trabajo para los pintores de Aragón.

Daniel Martínez no era un pintor desconocido en Zaragoza, antes de afincarse en esta capital, ya que en octubre de 1584 sabemos de su relación con su compatriota Rolán Mois a través de un préstamo que le hace el flamenco, quizás estuviera relacionado con una obra realizada en común y, en los primeros meses del siguiente, hay constancia de sus trabajos en el Monumento de Semana Santa, de la Seo zaragozana ${ }^{7}$. Los diferentes albaranes, algunos son autógrafos, emitidos a su favor por esta obra indican una renovación importante de la pintura de ese aparato efímero y cuando esto sucedía, el cabildo metropolitano siempre había contratado a los mejores pintores. Además, en esta ocasión el cabildo debió poner especial empeño en la obra, al pensar que quizás Felipe II y su corte, desplazada a Zaragoza para celebrar las bodas de la infanta Catalina Micaela con el duque de Saboya, se decidieran a pasar los días de Semana Santa en esta capital. Aunque no se cumplió esta expectativa, el monarca conmemoró la festividad litúrgica en el monasterio catalán de Poblet, el «Monumento» de Daniel Martínez se conservó hasta 1603, en cuya fecha fue innovado por el pintor Rafael Pertús, a quien tanto ensalza Jusepe en sus Discursos a propósito de sus «fantasías» en este tipo de obras. El maestro Daniel continuó en 1586 realizando diferentes trabajos para la Seo zaragozana, el más destacado debió ser «pintar el retablo del fosal», cuyo finiquito cobraba el 30 de enero del año siguiente ${ }^{8}$.

Martínez, que volvió después de esa fecha a Ejea, donde también se ocupó del Monumento de Semana Santa en 1588, retornaba a la capital del Ebro hacia 1600 y aquí comienza a ostentar el título de infanzón en la década de 1620, además de disfrutar ya entonces de una posición económica desahogada, que continuará hasta su muerte, ocurrida en Zaragoza el 19 de junio de 1636 (a la edad de 81 años) en su casa del callizo de Santa Catalina, cercana a la habitación y obrador de su hijo el célebre Jusepe Martínez.

6 Vid. V. González Hernández, Jusepe Martínez (1600-1682), Zaragoza, 1981, a este autor debemos la mayor parte de los datos conocidos sobre Daniel Martínez correspondientes al siglo XVII. El célebre Jusepe fue bautizado el 6 de diciembre de 1600. El dato de 1595 en C. Morte García, «Documentos sobre pintores y pintura del siglo XVI en Aragón.II», Boletín del Museo e Instituto "Camón Aznar», XXXI-XXXII, 1988, n. 386; en esa fecha quedaba cancelado el préstamo que Daniel tenía de su colega Rolam Mois desde 1584; en esta publicación se recogen otros muchos datos sobre Mois y Schepers. En el trabajo que presento ahora se dan nuevos datos sobre Martínez.

7 Se citan en varios documentos sueltos que se encuentran en el Archivo de la Seo de Zaragoza, recogidos como «Recibos de la fábrica del año 1585»; comienzan en enero y terminan el 26 de abril de ese año, en el último se especifica «yo daniel Martinez pintor atorgo de aber recibido del Ill(ustr)e señor canonigo Romero como fabriquero de la Seo de Çaragoça es a saber quince escudos por sastifaçion y estrenas de los muy Ill(ust) res señores prior y canonigos de la seo de Çaragoça de pintar el monumenta i por que es berdat hise el presente alberan de my mano a 26 del mes de ablil: al año 1585 yo daniel martinez atorgo lo sobredicho» (rúbrica). Con otra letra «El doctor Cerbuna prior». Los mismos datos figuran también en el Libro de Fabrica de 1585.

8 Zaragoza, Archivo de la Seo, Recibos de la Fábrica, año 1586 y 1587, en el último documento aparece firma y rúbrica del pintor. El cabildo también nombró a Martínez para tasar los trabajos del pintor Juan Ribera. 
De la actividad artística de Daniel, no se conocía hasta ahora obra segura y tanto las pinturas documentadas como las atribuidas, se localizaban en la comarca aragonesa de las Cinco Villas. En primer lugar, las pinturas murales atribuidas de la iglesia de San Andrés de Uncastillo, atribución apoyada en un documento emitido bastantes años después cuando su hijo se ocupaba del retablo mayor de Santa María, están fechadas en 1584 y a pesar de hallarse muy deterioradas, se observan varias manos en su ejecución y en otra ocasión ya advertí su relación con modelos de Mois, proponiendo a este último como director artístico de los trabajos, admitiendo la participación en los mismos de Daniel Martínez ${ }^{9}$. La siguiente obra era el retablo mayor de Longás documentado en 1601 que no se conserva ${ }^{10}$.

Nos planteamos ahora si Daniel Martínez realizó algún lienzo del antiguo retablo mayor de la iglesia de Santa María de Uncastillo y, en concreto, nos parece debe ser el que ocupa el ático donde se representa una Alegoría de la Sagrada Familia, cuyas formas artísticas están conectadas con el lenguaje pictórico de finales del siglo XVI (recordando sus modelos figurativos a los de los dos cuadros aquí estudiados), distinto al estilo del resto de los lienzos del retablo. Es posible que hubiera comenzado a pintar un retablo para la iglesia hacia 1619, en cuya fecha aparece en Uncastillo junto con su hijo Jusepe, ya pintor, lo cual podría explicar los pagos que en la década siguiente recibe Daniel de la primicia de la iglesia de Santa María de la localidad, retablo que fue sustituido por el encomendado a Jusepe Martínez en $1647^{11}$, quien en homenaje a su difunto padre debió incorporar el lienzo anterior y en recuerdo de un trabajo en común.

La posibilidad de identificar al autor del dibujo de la Sagrada Familia, con otros pintores activos por esas fechas en Aragón y cuya inicial del nombre y apellido coincidan con el texto del mismo, como sucede con Domingo Martínez documentado en Zaragoza entre 1589 y 1614, ofrece el problema de que su trabajo conocido está vinculado a labores de policromía y dorado de retablos y tallas, precisamente estas tareas son las contratadas por él en 1596 destinadas al retablo de la capilla funeraria de Mois en la iglesia del convento de Santo Domingo de Zaragoza, cuya gran tabla —obra del maestro flamenco- está en el Museo de Bellas Artes de la misma ciudad. Desconozco si este pintor puede ser el mismo que un Domingo del Camino citado por Jusepe Martínez en sus Discursos, como discípulo de Schepers.

La Sagrada Familia de la Seo de Zaragoza (fig. 7), inédita, pintada al óleo sobre tabla (98 x $71 \mathrm{~cm}$.), procede de un retablo de la antigua sacristía mayor según se lee en el reverso del marco, donde está escrito: «Cuadro del retablo que está en el almacén alto del retablo alto y que estubo en el retrete de la sacristía mayor». El texto se debió colocar a finales del siglo XVIII cuando se le puso el actual marco barroco. La pintura reproduce con bastante fidelidad el dibujo, tanto el esquema general de la composición, incluidos la cortina del fondo y el plato con frutas colocado encima del asiento corrido donde está la Virgen, como el número de personajes y sus posturas, excepto la ligera modificación introducida en la actitud de San José y en el rostro de María.

9 C. Morte García, «La iglesia de San Andrés de Uncastillo (Zaragoza), edificio funerario del siglo XVI del obispo Pedro del Frago», Artigrama, 1, 1984, pp. 147-176, con bibliografía.

10 A. San Vicente, «Acotaciones documentadas para la historia del arte de las Cinco Villas en el siglo XVI», Homenaje a D. Eugenio Frutos Cortés, Zaragoza, 1977, p. 395.

11 V. González, Jusepe, ob. cit, p. 16, da el dato de Daniel y de su hijo juntos en Uncástillo en 1619, en cambio atribuye todos los lienzos a Jusepe, criterio mantenido por los historiadores. El retablo se ha montado de nuevo —en 1998 — en la iglesia de San Juan. 

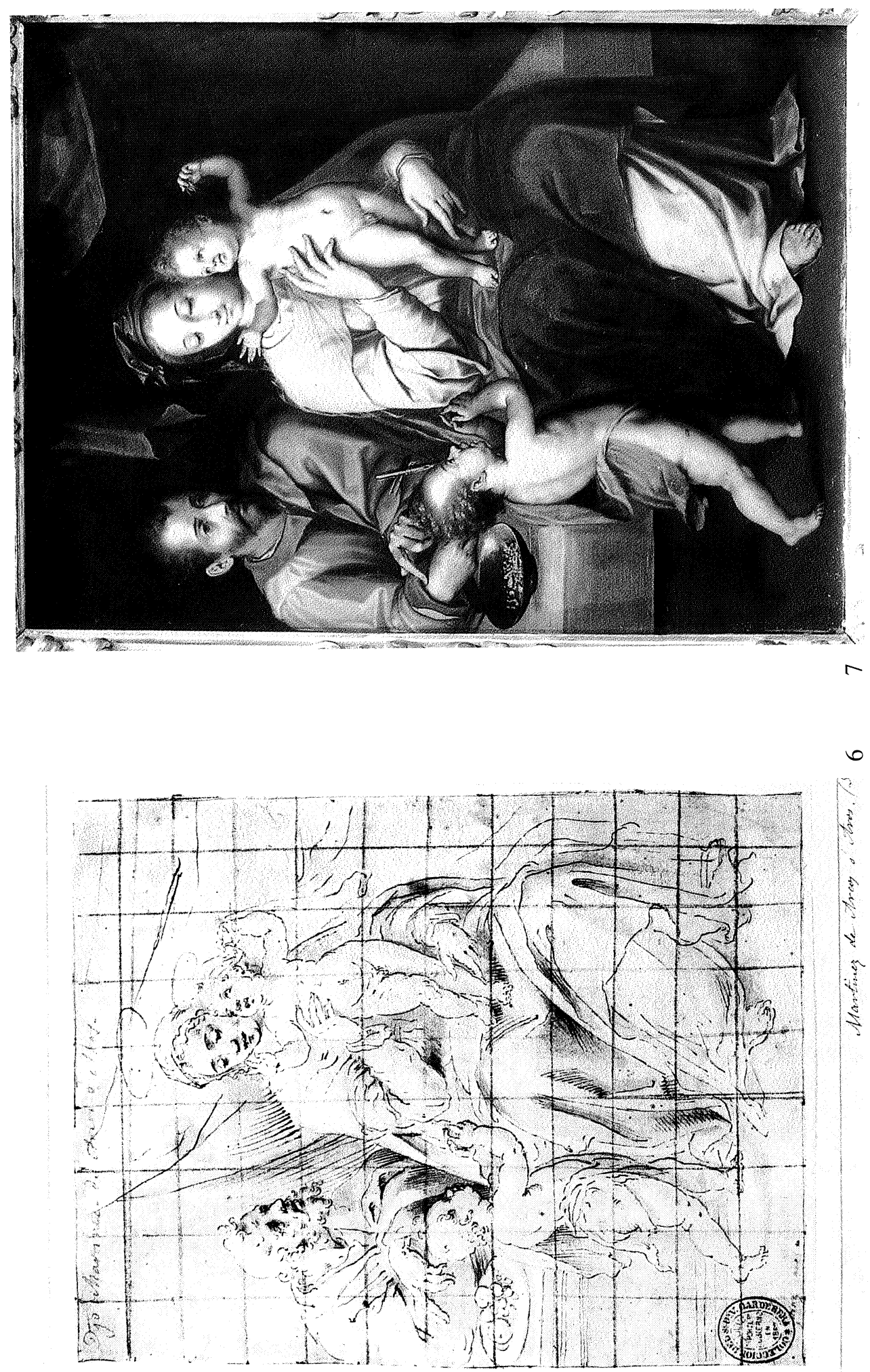

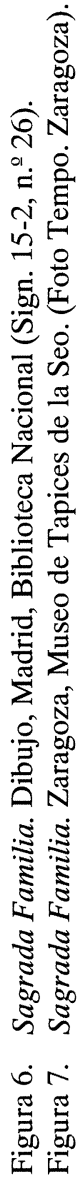


La pintura, por tanto, presenta aquellos estilemas de la pintura aragonesa del último cuarto del siglo XVI, introducidos con éxito por Schepers y Mois, relacionados con el lenguaje formal de la maniera de tono rafaelesco, y cuya afinidad estilística y de color con las obras antes citadas de estos dos maestros flamencos, es evidente. El ideal de belleza refinado del rostro redondeado de la Virgen, con los ojos bajos, es posible encontrarlo en la misma figura del cuadro de la Adoración de los Pastores del retablo de Tafalla y de un ejemplar del Museo de Zaragoza, modelo rafaelesco que recuerda a la Virgen de La Sagrada Familia, llamada «La Perla» (Museo del Prado, Madrid), obra de Rafael y Giulio Romano, incluso en este mismo cuadro se halla la tipología de San Juanito de formas robustas (fig. 9), similar indumentaria y postura de las piernas. Quizás estas coincidencias estén inspiradas en alguna estampa, se recuerda que el primer grabado conocido de la composición italiana se debe a Battista Franco (1498-1561). Los ecos de Rafael también se hallan en otros ejemplos tardíos de la pintura aragonesa, así como muestra podemos citar una Santa Generación del retablo de Nuestra Señora del Pilar, de la iglesia de Bureta, que en mi opinión se debe atribuir a Silvestre Estanmolín, donde se copia una estampa de Marcantonio Raimondi.

Los colores de la pintura se distribuyen de manera estudiada en los diversos planos espaciales, desde el fondo oscuro (amortiguado por la cortina verde pistacho), se pasa a los tonos tornasolados y tierras de la indumentaria de San José, y al plano central del asiento rojo (el único en gama cálida), hasta alcanzar el primer término de la composición ocupado con el rosa fuerte del vestido y el azul del manto de la Virgen, colorido que realza la sutil transparencia del velo, cuyas puntas sujetan la Madre y el Niño, intentando disimular su desnudez y buscando formas de ritmo equilibrado. La técnica de ejecución está realizada con esmero, mezclando la pincelada concreta y los contornos de las imágenes muy perfilados, con las suaves sombras en las carnaciones.
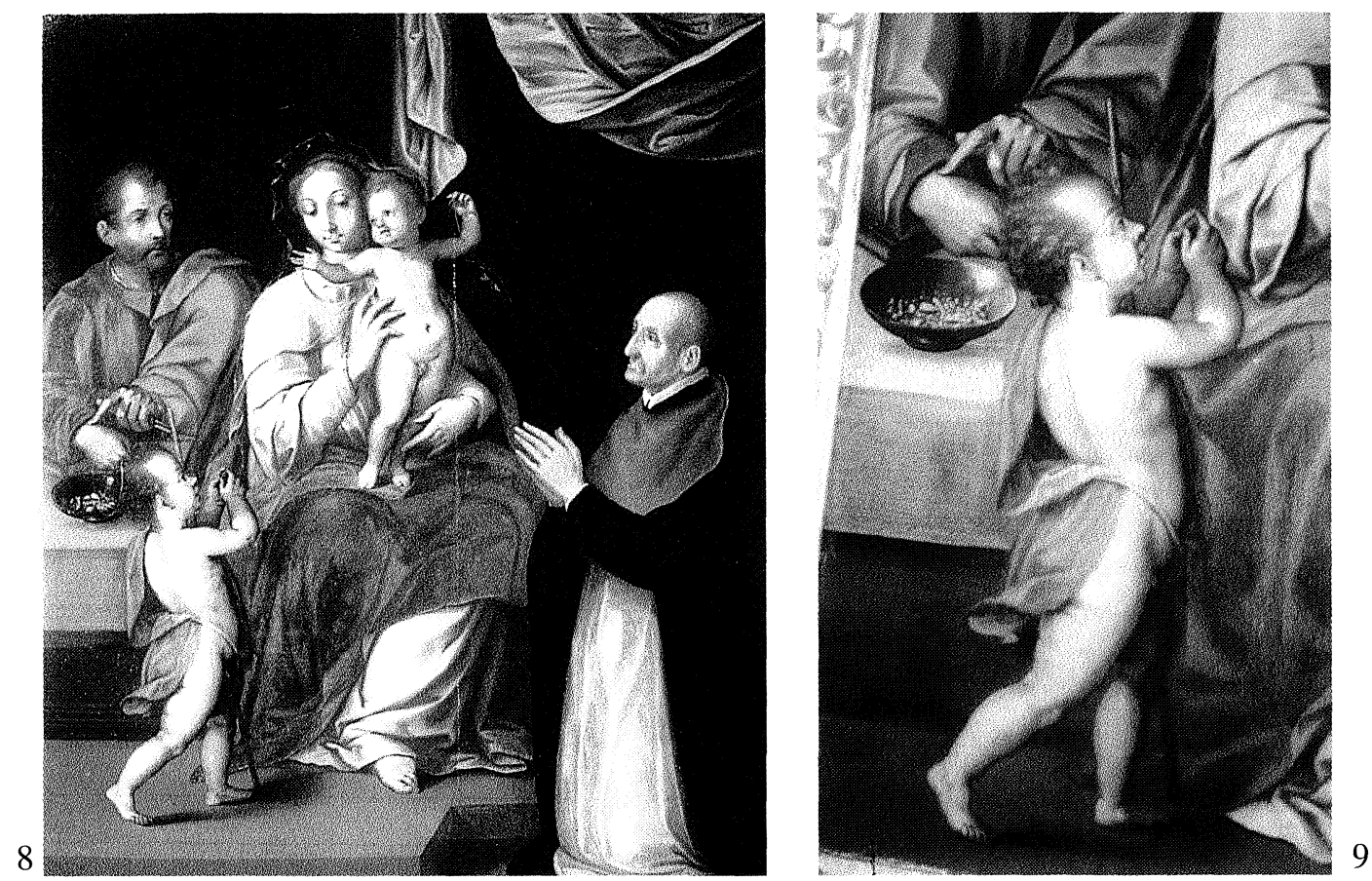

Figura 8. Sagrada Familia. Ejea de los Caballeros (Zaragoza), Parroquia de San Salvador, 1602. (Foto Tempo. Zaragoza).

Figura 9. San Juanito, detalle de la Sagrada Familia. Zaragoza. Museo de Tapices. 
Esta pintura pudo hacerla Daniel Martínez en 1585-1586 cuando realizaba las tareas comentadas en la Seo de Zaragoza o más bien cuando ya se traslada a vivir a la capital, entorno a 1600, por ser casi réplica de la de Ejea, fechada en 1602. Al pintor debió favorecerlo en ambas ocasiones Pascual Mandura, canónigo de la catedral y presidente del cabildo en la última fecha. Desconozco la advocación del citado retablo del fosal encomendado a Martínez, si bien la iconografía de este cuadro no parece la adecuada para colocarlo en un recinto funerario, en cambio sus labores en este templo son otro dato más para avalar la atribución de la pintura al padre de Jusepe Martínez.

La Sagrada Familia con donante (fig. 8), locălizada en la sacristía de la iglesia parroquial de San Salvador, de Ejea de los Caballeros, también está realizada al óleo sobre tabla $(115 \times 94 \mathrm{~cm}$.) y presenta marco de madera de la época de la pintura, adornado con abundante orla vegetal dorada. En el escalón y junto a la imagen del retratado se lee: «AETATIS. SUE. 75./ AÑO 1602». Creo se puede identificar con el canónigo Pascual Mandura ${ }^{12}$, natural de esa villa y racionero de la misma, que en el año del cuadro fundaba una serie de aniversarios en las iglesias de la localidad. La presencia de la obra se rastrea en los inventarios llevados a cabo del «mobiliario» existente en la sacristía de la iglesia del Salvador, a mediados del siglo XIX, donde se anotan «un cuadro al óleo de la Sagrada Familia y otro del canónigo Mandura» ${ }^{13}$.

Don Pascual Mandura, ilustre personalidad, autor de un interesante libro de Memorias sobre los acontecimientos de La Seo de Zaragoza, fue electo canónigo de esta catedral, «siendo prior del señor Cerbuna, â 28 de Agosto de 1579.... era Doctor theologo, y como tal se incorporo a la Universidad de Zaragoza dia primero de Diciembre de 1583 y fue Retor de la misma en los años 1585, 1590 y 1593: en el de 1592 fue hecho visitador del Arzobispado y ordinario de la Inquisicion en la sede vacante causada por la muerte del señor Arzobispo Bobadilla, que murio en las Cortes de Tarazona: murio à 27 de enero de 1604, y se enterro en la capilla de San Martin» ${ }^{14}$.

La pintura es una copia fiel del cuadro de Zaragoza del mismo tema, incluido el colorido y la técnica ${ }^{15}$. Las diferencias radican en el estrado del primer término que amplía el espacio, sin embargo se ha colocado por la necesidad de incorporar el retrato del donante en lugar destacado, pero situado en un plano inferior por su naturaleza humana. Va vestido con el hábito de canónigo reglar de San Agustín y destaca la cabeza de rasgos expresivos e individualizados, cuyo retrato contrasta con la idealización del resto de las imágenes. La figura del anciano eclesiástico no rompe la armonía de la composición y para no alterar el esquema de la Sagrada Familia anterior, la tela colgante de la cortina se sitúa detrás del Niño Jesús. El canónigo Mandura, habituado a contemplar el bello cuadro de la Sagrada Familia de su catedral, debió mandar copiarlo y quizás en un primer momento lo tuvo en sus aposentos como una obra de devoción particular. No resulta extraño que el clérigo favoreciera a Daniel Martínez, incluso entre ellos pudo existir algún lazo de parentesco a través de la familia de la mujer del pintor, originaria también de Ejea de los Caballeros.

12 Esta identificación ya la hice cuando di a conocer el cuadro en el catálogo de la exposición María en el arte de la Diócesis de Zaragoza, Zaragoza, 1988, n. ${ }^{\circ} 45$, pero en aquella ocasión no relacioné la pintura con el dibujo ni con Daniel Martínez.

13 Ejea, Archivo parroquial, Libro inventario de las tres iglesias, año 1851, f. 7; año 1876, f. 36. La fundación en idem, Libro de Procura-Fundaciones, ff. 1-4.

${ }_{14}$ Blas Mathias San Juan, Catálogo de las dignidades, canónigos y prelados de la Santa Iglesia de Zaragoza y su Universidad. Año 1770. (La Seo, manuscrito, f. 153). Dato comprobado en los Cinco Libros, tomo 3.․ Otros detalles biográficos en Ferrer Racax, Idea de Exea, 1799, pp. 175-178.

15 Esta pintura de Ejea ha perdido parte de las veladuras originales debido a una excesiva limpieza antigua. 
El padre de Jusepe Martínez se comporta en estas primeras obras como un discípulo de Schepers y Mois, sumándose así a los pintores Felices de Cáceres (+1618), Antonio Galcerán $(† 1618)$ y Silvestre Estanmolín († ca-1630), artífices en prolongar'los modelos de los maestros flamencos en la pintura aragonesa. Las obras nos parecen básicas para configurar la personalidad artística de Daniel Martínez.

CARMEn Morte García

Universidad de Zaragoza

\section{UNA OBRA INÉDITA DE LUIS MACHUCA: LA TORRE DE LA VELA, DE MOTRIL}

Durante el siglo XVI la principal defensa de la entonces villa de Motril (Granada), frontera abierta respecto a las aceifas bereberes, estaba constituida por la iglesia mayor, titulada de la Encarnación. Era, en principio, un templo de rasgos mudéjares, construido entre 1510 y 1514, con mampostería y encintados de ladriillo al exterior, cubierto interiormente por sólidas bóvedas de arista y provisto de dos pequeños accesos, orientados al sur y a poniente. El carácter fortificado de su fábrica se fue acrecentando a lo largo del Quinientos: desde al menos 1540 poseyó un aljibe de agua y varias dependencias para guardar bastimentos y armas; y, a mediados de la centuria, se almenó el conjunto y se colocaron sendos «ladrones» sobre las dos puertas. No obstante, los principales trabajos se llevaron a cabo sobre todo entre 1565 y 1568, en los años previos a la revuelta morisca. Consistieron aquéllos en la construcción de un revellín o recinto murado con dos cubos defensivos junto a la puerta sur, a modo de plaza de armas, y en rodear todo el perímetro de la iglesia de un foso y muros de tapial, con almenas y troneras. Finalmente, este sistema de defensa adaptado a las armas de artillería se completó con la construcción de dos torres abaluartadas en los flancos del templo ${ }^{1}$. De todo este conjunto defensivo sólo se conserva hoy la llamada Torre de la Vela, proyectada por Luis Machuca (figs. 10, 11 y 14).

En efecto, consta documentalmente que Luis Machuca dio en 1565 las «condiciones con las cuales se han de hacer los dos baluartes en la iglesia de Motril» ${ }^{2}$ : dos torres pentagonales, con casamata interior y troneras, en los ángulos sudoeste y nordeste del edificio. Por desgracia, aunque se conserva un traslado de las trazas originales del autor, falta el dibujo o plano explicativo que acompañaría a las mismas, cuyas condiciones eran las siguientes: la mezcla, consistente en 2 espuertas de cal y 1 de arena/ Los cimientos, ahondados «hasta hallar el buen fundamento», de cal, arena y piedra, se medirían tomando 17 pies desde las esquinas de la iglesia y a partir de ahí, para los costados, «guardando el punto que les será mostrado», con zanjas de la anchura de 10 ladrillos/ Los muros tendrían 8 ladrillos de grueso, dejando de releje 2 por la cara externa y dando de escarpa 1 de cada $5 / \mathrm{La}$ altura de aquéllos debía ser de 20 pies, repartidos en 6 hileras de cajones de mampuesto con 3 cintas de ladrillo en cada uno, reforzados con anchas rafas o hiladas de ladrillo en la esquina principal y en los

1 Cruz Cabrera, José Policarpo: «Las actas capitulares como fuente para la historia urbana: Motril en el siglo XVI». En Cuadernos de Arte, de la Universidad de Granada, n. ${ }^{\circ} 28,1997$, pp. 65-75.

2 Archivo Histórico de la Alhambra (A.H.A). Legajo 129-26. Escrituras sobre los baluartes de la villa de Motril, 1566-1568. Y Legajo 223-164. Petición de salario del pregonero Juan García. La Alhambra, 30 de enero de 1566. Las trazas de Machuca fueron realizadas en el otoño de 1565. 